Opinion

\title{
Yoga: A Potential Adjunct Therapy to Current Rehabilitation Pathways in Cardiac Conditions and Stroke
}

Tharshanah Thayabaranathan ${ }^{1,}{ }^{*}$, Jan Cameron ${ }^{1,2,3}$, Barbara Murphy ${ }^{3,4,5}$, Dominique A Cadilhac ${ }^{1,}$ 6

1. Stroke and Ageing Research, Department of Medicine, School of Clinical Sciences at Monash Health, Monash University, Clayton, Victoria, Australia;

E-Mails: $\quad$ tharshanah.thayabaranathan@monash.edu; jan.cameron@monash.edu; dominique.cadilhac@monash.edu

2. School of Nursing and Midwifery, Monash University, Clayton, Victoria, Australia

3. Australian Centre for Heart Health, Victoria, Australia; E-Mail: barbara.murphy@australianhearthealth.org.au

4. School of Psychological Sciences, University of Melbourne, Victoria, Australia

5. Faculty of Health, Deakin University, Victoria, Australia

6. Stroke Division, Florey Institute of Neuroscience and Mental Health, The University of Melbourne, Heidelberg, Victoria, Australia

* Correspondence: Tharshanah Thayabaranathan; E-Mail: tharshanah.thayabaranathan@monash.edu

Academic Editor: Marieke Van Puymbroeck

Collection: Yoga in Older Adults

OBM Geriatrics

2021, volume 5 , issue 1

doi:10.21926/obm.geriatr.2101155
Received: August 06, 2020

Accepted: January 14, 2021

Published: January 28, 2021

\section{Abstract}

Yoga is a form of movement-based mindfulness practice that enhances the mind-body connection to benefit overall health and well-being. Although the practices of yoga are ancient traditions in the Buddhist and Hindu philosophies, scientific research regarding the impacts of yoga among people with poor cardiovascular and cerebrovascular health has only recently been undertaken. In this article, we highlight the current evidence on the potential

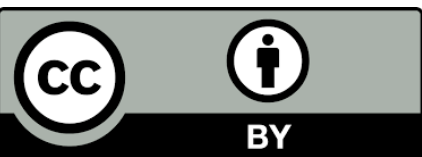

(C) 2021 by the author. This is an open access article distributed under the conditions of the Creative Commons by Attribution License, which permits unrestricted use, distribution, and reproduction in any medium or format, provided the original work is correctly cited. 
impact of yoga on physical and psychological well-being for older adults living with cardiac conditions or stroke.

\section{Keywords}

Yoga; mindfulness; elderly; stroke; heart failure; rehabilitation

\section{Introduction}

Globally, cardiac conditions and stroke are leading causes of mortality and morbidity affecting more than $25 \%$ of older adults particularly those over the age of 65 years $[1,2]$. Moreover, the prevalence of anxiety, depression and emotional distress in older adults living with the consequences of cardiac conditions or stroke is large (between 30-50\%), in particular for those with multiple comorbidity [3-8]. The lack of ability to self-manage the physical and psychological impacts of stroke or heart disease, lack of knowledge on coping strategies, and increased fear of experiencing another event leads to reduced medication adherence, poor quality of life, and social isolation [9-12].

Traditional rehabilitation and prevention strategies, including physical or pharmaceutical interventions, are strongly recommended to improve optimal functioning after a cardiac or stroke event $[13,14]$. Exercise has well-documented health benefits, but survivors of cardiac conditions or stroke often find it difficult to participate in, or follow, exercise regimens particularly when they are physically frail, or have additional comorbidities and vulnerable psychosocial health [15-17]. Traditional cardiac rehabilitation strategies primarily focus on physical recovery, as well as secondary prevention of cardiovascular disease through lifestyle behaviour modifications. Nonetheless, attendance at traditional outpatient-based cardiac rehabilitation programs is poor, particularly amongst those who are older [18-21]. Indeed, older age and the presence of comorbidities reduce the likelihood of referral to exercise-based cardiac rehabilitation programs [17]. Traditional stroke rehabilitation strategies are also exercise-driven and often designed to optimise functional motor performance [22]. There is a growing interest to direct survivors of stroke to cardiac rehabilitation programs, but the benefits of such programs are unclear [23, 24]. Many older adults are missing out on current rehabilitation strategies that support physical and psychological recovery following life-changing cardiovascular and cerebrovascular events [25].

\section{The Components and Potential Benefits of Yoga}

Yoga originated from Buddhist and Hindu philosophies and has been a traditional Indian spiritual practice for thousands of years [26]. Regardless of its origins, yoga has recently become popular in many western countries as an alternate method to physical and mental well-being [27-29]. Yoga is proposed to provide benefits by the promotion of mindfulness through low-impact movement, breathing and meditation [30,31]. The physical component of yoga involves low-impact movements that are combined with breathing techniques and mindfulness meditation. Mindfulness meditation, through focused attention, is essentially mental training that allows an individual to be in the 
current moment, thereby regulating emotions, help with acceptance of events, problems, and negative thoughts [32].

There is emerging evidence that yoga, a form of movement-based mindfulness intervention, might be a promising adjunct activity in addition to contemporary rehabilitation strategies to support the needs of people living with cardiac conditions or stroke [29, 33-35]. Some of the benefits provided by yoga including improving flexibility, strength, balance, emotional regulation, overall well-being and reducing stress, are common to other forms of physical activity [33, 36-40].

In this paper, we highlight the current evidence for the potential benefits of yoga in improving risk factor profiles in older adults living with cardiac conditions or stroke. While previous articles have covered aspects of this topic for stroke or cardiac conditions separately, none have brought these together into a single opinion article focusing on older adults with these conditions as provided here.

\section{Changes to Cardiovascular and Cerebrovascular Risk Profiles}

There are many common modifiable risk factors associated with cardiac conditions and stroke, including hypercholesterolemia, hypertension, diabetes, physical inactivity, unhealthy diet, cigarette smoking, being overweight or obese, excessive alcohol intake and mood disorders [41]. As more studies are undertaken, there is emerging albeit preliminary evidence that yoga can ameliorate some of these risk factors in adults generally, and specifically in older adults with chronic disease. Often older adults living with cardiac conditions or stroke have more than one risk factor which adds to the complexity of developing successful lifestyle and behaviour action plans to improve survival.

\subsection{High Blood Pressure, Diabetes, Cholesterol and Body Mass}

Hypertension is the most common risk factor in older adults with cardiac conditions or stroke. Emerging studies highlight the benefits of yoga in reducing blood pressure in older adults [42]. In a study of older adults with metabolic conditions who completed a one-year intervention with three hourly yoga classes per week, participants had a clinically and statistically significant mean reduction in systolic and diastolic blood pressure when compared to the control group (systolic blood pressure: $6.5 \mathrm{mmHg}$ vs $2.6 \mathrm{mmHg}$; diastolic blood pressure: $3.6 \mathrm{mmHg}$ vs $1.6 \mathrm{mmHg}$ ), and improved quality of life [43]. In another study of 170 people with heart disease randomly allocated to yoga and nonyoga groups, those in the yoga group had significantly greater improvements in systolic $(p<.002)$ and diastolic blood pressure $(p<.009)$ at 6 months post-intervention [44].

There is varying evidence of yoga on improving diabetic and blood cholesterol profiles, and reducing body fat, in adults with these risk factors $[43,45,46]$. In the comparative study of 170 people with heart disease, those in the yoga group showed significantly greater improvements in total cholesterol $(p<.0001)$, low density lipoprotein (LDL) levels $(p<.04)$ and triglycerides $(p<.00001)$ [44]. A study of people with diabetes similarly demonstrated significant improvements in blood cholesterol, as well as in blood glucose.[45] On the contrary, no improvement in blood glucose or cholesterol levels was gained through yoga for people with metabolic syndrome [43]. In terms of body fat, significant improvements from yoga have been seen in studies of people with heart disease [44]. However, many of these studies are not conducted exclusively in individuals who are older, or in those living with cardiac conditions or stroke. Most studies are further limited by small trial 
sample sizes, heterogeneity in their design, unclear or high risk of bias on several domains, and low to moderate quality of study designs [33].

\subsection{Smoking Cessation}

While smoking is a major risk factor for cardiac conditions or stroke, cessation of smoking has proved to be a highly effective strategy for improved health, and prevention of recurrent events [47]. The evidence of yoga as a therapy for smoking cessation in older adults diagnosed with cardiac conditions or stroke is scarce. In studies that assessed the potential for yoga and mindfulness to support smoking cessation, the interventions produced changes in smoking behaviour, and in predictors of smoking behaviour such as, decreased number of cigarettes smoked, lower levels of cravings and attitudinal changes regards smoking. However, definite conclusions on their benefits for smoking cessation is not possible due to the lack of well-designed studies [48].

\subsection{Unhealthy Diet and Excessive Alcohol}

To our knowledge there have been no studies designed to assess the effectiveness of yoga on unhealthy diet or alcohol consumption in older adults living with cardiac conditions or stroke.

\subsection{Other Cardiovascular Indicators}

Both heart rate variability and endothelial function are also indicators of cardiovascular health. In a recent randomised controlled trial involving 80 heart attack survivors, participants in a 12-week yoga-based cardiac rehabilitation program had favourable effects on heart rate variability (HRV) compared to participants in a standard care cardiac rehabilitation involving only education [49]. In a pilot study involving 33 people who were in a 6-week yoga program, those with an established heart disease $(n=10)$ observed a modest improvement in endothelial function from pre- to postprogram $(p<.09)[50]$.

\section{Benefits on Psychological Health}

Stress, anxiety and depression are commonly experienced in older adults living with cardiac conditions or stroke, and predict recurrent events and further comorbidities [4, 51-53]. Negative thoughts trigger the amygdala in the brain and cause heightened anxiety, and a stress response thereby affecting recovery [54].

Several strategies have been suggested for the treatment of anxiety and depression in patients with cardiac conditions or stroke such as pharmacotherapy, psychotherapy, and physical exercise $[55,56]$. However, these strategies might not be effective or ideal for some older adults with severe comorbidities. For example, antidepressant medications may be beneficial for some patients with cardiac conditions or stroke, but many of these drugs either interact with medications or have adverse cardiovascular effects (e.g. high blood pressure, abnormal heart beats) [57]. For these reasons, their use is limited in older adults with cardiac conditions or stroke.

Yoga may be an effective non-invasive adjunct strategy for the management of stress, anxiety and depression $[58,59]$. Three pilot studies have demonstrated that yoga has mental health benefits, in terms of improved mood, increased confidence, and reduced stress and anxiety, for people with heart disease [40], heart failure [39], and stroke [59]. Evidence suggests that the mechanisms by 
which emotional regulation is attained by yoga is via the hypothalamic-pituitary-adrenal (HPA) axis which then reduces cortisol levels in plasma, as well as reduced sympathetic nervous system tone, increase vagal activity, and elevate brain gamma-Aminobutyric acid levels, thereby reducing stress and improving emotional regulation [60-63]. Yoga seems to create awareness of emotions and acceptance, which assists with letting go of negative experiences, and builds confidence in those with poor psychological health.

\section{Inability to do Intense Physical Activity}

Promoting physical activity is a recommended evidence-based strategy for older adults. Recommendations include at least 30 minutes of moderate intensity exercise on most days of the week, and strength training two or three times a week [64]. However, the evidence supporting the intensity of physical activity for older adults with a cardiac condition or stroke is unclear. Older adults with compromised heart function, significant residual physical impairments from stroke, or with comorbid conditions that impact on physical health such as chronic obstructive pulmonary disease (COPD), peripheral vascular disease (PVD), or arthritis, are often unable to participate in intense physical activities [65]. Yoga may represent an appropriate adjunct to current exercise intensive rehabilitation strategies for older adults with chronic illness, particularly those with comorbid conditions [66]. Yoga can be tailored to suit the mobility or disability levels of each participant whereby modifications, such as chair-based yoga for those requiring or desiring more support, is feasible $[40,67]$.

\section{Social Isolation}

People who live alone may suffer from social isolation which tends to disproportionately affect older adults. Social isolation and loneliness are strongly associated with poor physical health and reduced psychological wellbeing $[11,12]$. This is particularly problematic in those living with cardiac conditions or stroke, potentially leading to inappropriate lifestyle choices including unhealthy diet, high alcohol consumption, excessive smoking, social withdrawal and reduced physical abilities, each further contributing to poor mental health $[11,12]$.

In recent times, people around the world are more than ever asked to socially isolate because of the novel coronavirus (COVID-19) pandemic, particularly older adults who are highly vulnerable and susceptible to the illness. The impact of social isolation is heightened in these unprecedented times, and the uncertainty of the pandemic on individuals' mental health is concerning [68]. In those older adults who are impacted by social isolation, there are obvious signs of psychological distress and fears of illness, death, and countless uncertainties about the future. In these circumstances, yoga can be delivered via virtual platforms, thereby potentially helping to regulate risk factors, alleviate symptoms of psychological distress and improve quality of life in older vulnerable adults.

\section{Conclusions and Future Directions}

In this article, we have highlighted the current evidence on the potential impact of yoga on physical and psychological well-being for older adults living with cardiac conditions or stroke. Available evidence suggests a potential positive impact of yoga on some modifiable cardiovascular and cerebrovascular risk factors in vulnerable older adults. Yoga can help to reduce stress, 
depression and anxiety and can possibly be an appropriate, feasible and adjunct form of rehabilitation therapy for older adults who are unable or unwilling to participate in other traditional physical training programs. The physiological mechanisms underlying the observed clinical effects of yoga on cardiovascular risk remains unclear. Future well-designed randomised clinical trials are warranted to determine the feasibility and efficacy of yoga in older adults with cardiac conditions or stroke. These trials should consider a rigorous design, larger sample sizes, should assess frequency and duration of yoga sessions, adherence of patients to yoga sessions, relevant patient outcomes, and include sufficient follow-up periods. The use of yoga as a stand-alone therapy in the older vulnerable population needs to be further explored.

\section{Author Contributions}

TT and DAC conceived the outline for the article. TT wrote the initial draft. JC, BM, DAC contributed to the first draft. All authors read, contributed to and approved the final version.

\section{Funding}

DAC was supported by a fellowship from the National Health and Medical Research Council (\#1154273).

\section{Competing Interests}

DAC and JC report grants from National Health and Medical Research Council outside the submitted work. DAC also reports grants from Queensland Health, Stroke Foundation, Heart Foundation, Boehringer Ingelheim, Medtronic, Shire, Pfizer, Amgen, Bristol-Myers Squibb, Agency for Clinical Innovation South Australian government, Department of Health, Western Australia, nonfinancial support from Zunyi Medical University, China, grants from National Institute Health Research (UK), and the Health Research Council (NZ) outside the submitted work. BM reports grants from the National Heart Foundation of Australia and HCF Research Foundation outside the submitted work. No other competing interests to declare.

\section{References}

1. Australian Institute of Health and Welfare. Cardiovascular disease. Canberra: AlHW; 2020.

2. Yazdanyar A, Newman AB. The burden of cardiovascular disease in the elderly: Morbidity, mortality, and costs. Clin Geriatr Med. 2009; 25: 563-577.

3. Eriksson M, Asplund K, Glader EL, Norrving B, Stegmayr B, Terént A, et al. Self-reported depression and use of antidepressants after stroke: A national survey. Stroke. 2004; 35: 936941.

4. Morrison V, Pollard B, Johnston M, MacWalter R. Anxiety and depression 3 years following stroke: Demographic, clinical, and psychological predictors. J Psychosom Res. 2005; 59: 209-213.

5. Murphy B, Le Grande M, Alvarenga M, Worcester M, Jackson A. Anxiety and depression after a cardiac event: Prevalence and predictors. Front Psychol. 2020; 10: 3010.

6. Thombs BD, Bass EB, Ford DE, Stewart KJ, Tsilidis KK, Patel U, et al. Prevalence of depression in survivors of acute myocardial infarction: Review of the evidence. J Gen Intern Med. 2006; 21: 30-38. 
7. Tully PJ, Baker RA. Depression, anxiety, and cardiac morbidity outcomes after coronary artery bypass surgery: A contemporary and practical review. J Geriatr Cardiol. 2012; 9: 197-208.

8. Thayabaranathan T, Andrew NE, Kilkenny MF, Stolwyk R, Thrift AG, Grimley R, et al. Factors influencing self-reported anxiety or depression following stroke or TIA using linked registry and hospital data. Qual Life Res. 2018; 27: 3145-3155.

9. Al AlShaikh S, Quinn T, Dunn W, Walters M, Dawson J. Predictive factors of non-adherence to secondary preventative medication after stroke or transient ischaemic attack: A systematic review and meta-analyses. Eur Stroke J. 2016; 1: 65-75.

10. Rochette A, Tribble DS-C, Desrosiers J, Bravo G, Bourget A. Adaptation and coping following a first stroke: A qualitative analysis of a phenomenological orientation. Int J Rehabil Res. 2006; 29: 247-249.

11. Jackson A, Murphy B. Loneliness, social isolation and cardiovascular risk. Br J Card Nurs. 2019; 14: 1-8.

12. Yu B, Steptoe A, Chen LJ, Chen YH, Lin CH, Ku PW. Social isolation, loneliness, and all-cause mortality in patients with cardiovascular disease: A 10-year follow-up Study. Psychosom Med. 2020; 82: 208-214.

13. Stroke Foundation. Clinical Guidelines for Stroke Management. Melbourne Australia. 2020.

14. Atherton JJ, Sindone A, De Pasquale CG, Driscoll A, MacDonald PS, Hopper I, et al. National Heart Foundation of Australia and Cardiac Society of Australia and New Zealand: Guidelines for the prevention, detection, and management of heart failure in Australia 2018. Heart Lung Circ. 2018; 27: 1123-1208.

15. Lui SK, Nguyen MH. Elderly stroke rehabilitation: Overcoming the complications and its associated challenges. Curr Gerontol Geriatr Res. 2018; 2018: 9853837.

16. Pardaens S, De Smedt D, De Bacquer D, Willems AM, Verstreken S, De Sutter J. Comorbidities and psychosocial characteristics as determinants of dropout in outpatient cardiac rehabilitation. J Cardiovasc Nurs. 2017; 32: 14-21.

17. Jackson L, Leclerc J, Erskine Y, Linden W. Getting the most out of cardiac rehabilitation: a review of referral and adherence predictors. Heart. 2005; 91: 10-14.

18. Worcester MU, Murphy BM, Mee VK, Roberts SB, Goble AJ. Cardiac rehabilitation programmes: Predictors of non-attendance and drop-out. Eur J Cardiovasc Prev Rehabil. 2004; 11: 328-335.

19. Hendriks J, Andreae C, Ågren S, Eriksson H, Hjelm C, Walfridsson U, et al. Cardiac disease and stroke: Practical implications for personalised care in cardiac-stroke patients. A state of the art review supported by the Association of Cardiovascular Nursing and Allied Professions. Eur J Cardiovasc Nur. 2020; 19: 495-504.

20. Borg S, Öberg B, Leosdottir M, Lindolm D, Nilsson L, Bäck M. Factors associated with nonattendance at exercise-based cardiac rehabilitation. BMC Sports Sci Med Rehabilitation. 2019; 11: 13.

21. Kotseva K, Wood D, De Bacquer D. Determinants of participation and risk factor control according to attendance in cardiac rehabilitation programmes in coronary patients in Europe: EUROASPIRE IV survey. Eur J Prev Cardiol. 2018; 25: 1242-1251.

22. Gordon NF, Gulanick M, Costa F, Fletcher G, Franklin BA, Roth EJ, et al. Physical activity and exercise recommendations for stroke survivors. Circulation. 2004; 109: 2031-2041.

23. Cuccurullo SJ, Fleming TK, Kostis WJ, Greiss C, Gizzi MS, Eckert A, et al. Impact of a stroke recovery program integrating modified cardiac rehabilitation on all-cause mortality, 
cardiovascular performance and functional performance. Am J Phys Med Rehabil. 2019; 98: 953-963.

24. Mackay-Lyons $M$, Thornton $M$, Ruggles $T$, Che $M$. Non-pharmacological interventions for preventing secondary vascular events after stroke or transient ischemic attack. Cochrane Database Syst Rev. 2013; 3: CD008656.

25. McPhee JS, French DP, Jackson D, Nazroo J, Pendleton N, Degens H. Physical activity in older age: Perspectives for healthy ageing and frailty. Biogerontology. 2016; 17: 567-580.

26. Vohra-Gupta S, Russell A, Lo E. Meditation: The adoption of Eastern thought to Western social practices. J Relig Spiritual Soc Work. 2007; 26: 49-61.

27. Bastille JV, Gill-Body KM. A yoga-based exercise program for people with chronic poststroke hemiparesis. Phys Ther. 2004; 84: 33-48.

28. Chan W, Immink MA, Hillier S. Yoga and Exercise for symptoms of depression and anxiety in people with poststroke disability: A randomised, controlled pilot trial. Altern Ther. 2012; 18: 3443.

29. Yeung AC, Chang D, Bensoussan A, Kiat H. Yoga and cardiac rehabilitation: A brief review of evidence. J Yoga Phys Ther. 2015; 5: 1000207.

30. Dusek JA, Benson H. Mind-Body Medicine: A model of the comparative clinical impact of the acute stress and relaxation responses. Minn Med. 2009; 92: 47-50.

31. Evans E, Tsao JC, Sternlieb B, Zeltzer LK. Using the biopsychosocial model to understand the health benefits of yoga. J Complement Integr Med. 2009; 6. Doi: 10.2202/1553-3840.1183.

32. Telles $S$, Singh N. Science of the mind: Ancient yoga texts and modern studies. Psychiatr Clin. 2013; 36: 93-108.

33. Thayabaranathan $T$, Andrew NE, Immink MA, Hillier S, Stevens $P$, Stolwyk R, et al. Determining the potential benefits of yoga in chronic stroke care: A systematic review and meta-analysis. Top Stroke Rehabil. 2017; 24: 279-287.

34. Lawrence M, Celestino Junior FT, Matozinho HH, Govan L, Booth J, Beecher J. Yoga for stroke rehabilitation. Cochrane Database Syst Rev. 2017; 12: CD011483.

35. Kwong JS, Lau HL, Yeung F, Chau PH, Woo J. Yoga for secondary prevention of coronary heart disease. Cochrane Database Syst Rev. 2015; 6: CD009506.

36. Lakkireddy D, Atkins D, Pillarisetti J, Ryschon K, Bommana S, Drisko J, et al. Effect of yoga on arrhythmia burden, anxiety, depression, and quality of life in paroxysmal afibrillation. J Am Coll Cardiol. 2013; 61: 1177-1182.

37. Roland KP, Jakobi JM, Jones GR. Does yoga engender fitness in older adults? A critical review. J Aging Phys Activ. 2011; 19: 62-79.

38. Yeung A, Kiat H, Denniss AR, Cheema BS, Bensoussan A, Machliss B, et al. Randomised controlled trial of a 12 week yoga intervention on negative affective states, cardiovascular and cognitive function in post-cardiac rehabilitation patients. BMC Complement Altern Med. 2014; 14: 411.

39. Howie-Esquivel J, Lee J, Collier G, Mehling W, Fleischmann K. Yoga in heart failure patients: A pilot study. J Card Fail. 2010; 16: 742-749.

40. Murphy B, Zaman S, Tucker KA, Alvarenga M, Morrison-Jack J, Higgins R, et al. Enhancing the appeal of cardiac rehabilitation for women: Development and piloting of a women-only yoga CR program. Eur J Cardiovasc Nurs. 2020.

41. Arboix A. Cardiovascular risk factors for acute stroke: Risk profiles in the different subtypes of ischemic stroke. World J Clin Cases. 2015; 3: 418-429. 
42. Santaella DF, Devesa CR, Rojo MR, Amato MB, Drager LF, Casali KR, et al. Yoga respiratory training improves respiratory function and cardiac sympathovagal balance in elderly subjects: $A$ randomised controlled trial. BMJ Open. 2011; 1: e000085.

43. Siu PM, Yu AP, Benzie IF, Woo J. Effects of 1-year yoga on cardiovascular risk factors in middleaged and older adults with metabolic syndrome: A randomized trial. Diabetol Metab Syndr. 2015; 7: 40.

44. Pal A, Srivastava N, Tiwari S, Verma NS, Narain VS, Agrawal GG, et al. Effect of yogic practices on lipid profile and body fat composition in patients of coronary artery disease. Complement Ther Med. 2011; 19: 122-127.

45. Gordon LA, Morrison EY, McGrowder DA, Young R, Fraser YT, Zamora EM, et al. Effect of exercise therapy on lipid profile and oxidative stress indicators in patients with type 2 diabetes. BMC Complement Altern Med. 2008; 8: 21.

46. McDermott KA, Rao MR, Nagarathna R, Murphy EJ, Burke A, Nagendra RH, et al. A yoga intervention for type 2 diabetes risk reduction: $A$ pilot randomized controlled trial. BMC Complement Altern Med. 2014; 14: 212.

47. Duncan MS, Freiberg MS, Greevy RA, Kundu S, Vasan RS, Tindle HA. Association of smoking cessation with subsequent risk of cardiovascular disease. JAMA. 2019; 322: 642-650.

48. Carim-Todd L, Mitchell SH, Oken BS. Mind-body practices: An alternative, drug-free treatment for smoking cessation? A systematic review of the literature. Drug Alcohol Depend. 2013; 132: 399-410.

49. Christa E, Srivastava P, Chandran DS, Jaryal AK, Yadav RK, Roy A, et al. Effect of yoga-cased cardiac rehabilitation on heart rate variability: Randomized controlled trial in patients post-MI. Int J Yoga Therap. 2019; 29: 43-50.

50. Sivasankaran S, Pollard-Quintner S, Sachdeva R, Pugeda J, Hoq SM, Zarich SW. The effect of a six-week program of yoga and meditation on brachial artery reactivity: Do psychosocial interventions affect vascular tone? Clin Cardiol. 2006; 29: 393-398.

51. Staub F, Carota A. Depression and fatigue after stroke. In: Recovery after stroke. Cambridge: Cambridge University Press; 2005.

52. Ayerbe L, Ayis S, Wolfe CD, Rudd AG. Natural history, predictors and outcomes of depression after stroke: Systematic review and meta-analysis. Br J Psychiat. 2013; 202: 14-21.

53. Murphy B, Higgins R, Jackson A. Anxiety, depression and psychological adjustment after an acute cardiac event. Singapore: Springer; 2016.

54. Fowler $\mathrm{CH}$, Miernicki ME, Rudolph KD, Telzer EH. Disrupted amygdala-prefrontal connectivity during emotion regulation links stress-reactive rumination and adolescent depressive symptoms. Dev Cogn Neurosci. 2017; 27: 99-106.

55. Davidson JR. Major depressive disorder treatment guidelines in America and Europe. J Clin Psychiatry. 2010; 71 (Suppl E1): e04.

56. Carek PJ, Laibstain SE, Carek SM. Exercise for the treatment of depression and anxiety. Int J Psychiat Med. 2011; 41: 15-28.

57. Yekehtaz H, Farokhnia M, Akhondzadeh S. Cardiovascular considerations in antidepressant therapy: An evidence-based review. J Tehran Heart Cent. 2013; 8: 169-176.

58. Lee KC, Tang WK, Bressington D. The experience of mindful yoga for older adults with depression. J Psychiatr Ment Health Nurs. 2019; 26: 87-100.

59. Garrett R, Immink MA, Hillier S. Becoming connected: The lived experience of yoga participation 
after stroke. Disabil Rehabil. 2011; 33: 2404-2415.

60. Streeter CC, Jensen JE, Perlmutter RM, Cabral HJ, Tian H, Terhune DB, et al. Yoga asana sessions increase brain GABA levels: A pilot tudy. J Altern Complement Med. 2007; 13: 419-426.

61. Streeter CC, Gerbarg PL, Saper RB, Ciraulo DA, Brown RP. Effects of yoga on the autonomic nervous system, gamma-aminobutyric-acid, and allostasis in epilepsy, depression, and posttraumatic stress disorder. Med Hypotheses. 2012; 78: 571-579.

62. Riley KE, Park CL. How does yoga reduce stress? A systematic review of mechanisms of change and guide to future inquiry. Health Psychol Rev. 2015; 9: 379-396.

63. Gard T, Noggle JJ, Park CL, Vago DR, Wilson A. Potential self-regulatory mechanisms of yoga for psychological health. Front Hum Neurosci. 2014; 8: 770.

64. Brown WJ, Bauman AE, Bull F, Burton NW. Development of Evidence-based Physical Activity Recommendations for Adults (18-64 years). Report prepared for the Australian Government Department of Health. Canberra: Commonwealth of Australia; 2012.

65. Sundararajan V, Begg S, Marshall R, Bunker SJ, McBurney H. Attendance rates and outcomes of cardiac rehabilitation in Victoria, 1998. Med J Aust. 2004; 180: 268-271.

66. GroessI EJ, Maiya M, SchmalzI L, Wing D, Jeste DV. Yoga to prevent mobility limitations in older adults: feasibility of a randomized controlled trial. BMC Geriatr. 2018; 18: 306.

67. Guddeti RR, Dang G, Williams MA, Alla VM. Role of yoga in cardiac disease and rehabilitation. J Cardiopulm Rehabil Prev. 2019; 39: 146-152.

68. Armitage R, Nellums LB. COVID-19 and the consequences of isolating the elderly. Lancet Public Health. 2020; 5: e256.

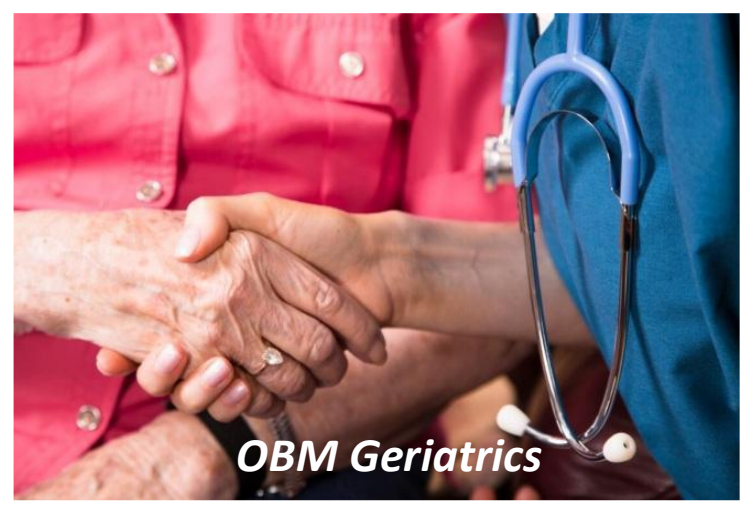

Enjoy $O B M$ Geriatrics by:

1. Submitting a manuscript

2. Joining in volunteer reviewer bank

3. Joining Editorial Board

4. Guest editing a special issue

For more details, please visit: http://www.lidsen.com/journals/geriatrics 